\title{
Some Aspects of Numerical Modeling of Steel-Concrete Composite Beams with Prestressed Tendons
}

\author{
Jorge Luis Palomino Tamayo ${ }^{a^{*}}$ (ic \\ Marina lara Franco ${ }^{a}$ (iD) \\ Inácio Benvegnu Morsch ${ }^{a}$ \\ Jean Marie Désira \\ Alvaro Marcelo Moscoso Wayar ${ }^{b}$ \\ a Departamento de Engenharia Civil, Escola de Engenharia, Universidade Federal do Rio Grande do Sul, Av. Osvaldo Aranha 99-3 andar, \\ 90035-190, Porto Alegre, RS, Brasil. Email: jorge.tamayo@ufrgs.br, marinaiarafranco@gmail.com, morsch@ufrgs.br, jean.marie@ufrgs.br \\ ${ }^{\text {b }}$ Departamento de Ingeniería Civil, Escuela de Arquitectura e Ingeniería, Universidad Privada Boliviana, Camino Achocalla km 2.5-Sector \\ Kañuma, La Paz, Bolivia. Email: alvaromoscoso@Ip.upb.edu
}

* Corresponding author

http://dx.doi.org/10.1590/1679-78255599

\begin{abstract}
Aspects about the numerical modeling of three-dimensional prestressed steel-concrete composite beams by using the finite element (FE) method are highlighted and commented in this work. Emphasis is given to the numerical treatment of bonded and unbonded tendons. The proposed modeling technique uses curved beam and catenary elements for simulating internal and external tendons, respectively. Other issues such as the constitutive model for shear connectors, steel beam and concrete are also discussed. Several numerical examples with experimental and numerical results are presented. It is encountered that a faster numerical convergence is achieved when the tendon stiffness is included in the overall stiffness of the structure, even when the unbonded internal situation is addressed. Moreover, omitting slipping at the deviator device may lead to inaccurate results in the evaluation of tendon forces for external prestressing. Favourable agreement is encountered for all studied examples.
\end{abstract}

\section{Keywords}

Steel-concrete composite beams, time effects, relaxation, tendon.

\section{INTRODUCTION}

Steel-concrete composite beams are widely used in civil constructions, and their use include the construction of roofs, floors in buildings and superstructures in long-span bridges, hence constituting an active research field. The composite beam is comprised of a reinforced concrete $(\mathrm{RC})$ slab partially or fully connected to a steel beam by means of shear connectors. In this manner, the strength and stiffness of both materials are better exploited compositely, i.e., the steel acts in tension while concrete in compression. Also, prestressing induced by internal or external tendons is a commonly utilized technique to enhace the performance of the composite section, as it occurs in strengthening and retroffiting of existing structures. The benefits of prestresing are related to a better control of concrete cracking at negative flexural regions (i.e., interior supports) and to the increment of the ultimate beam flexural capacity, for instance. Therefore, an accurate analysis of the structure is needed to satisfy the requirements of strength and 
serviceability limit states. This can be accomplished by using a FE based approach, in which all issues linked to material behavior, such as slipping at the slab-beam interface, concrete cracking, concrete crushing, shear transfer by aggregate interlock, shear failure of connectors, failure of prestressed and ordinary reinforcements, and yielding of the steel beam are incorporated. Furthermore, the high cost of experiments and the difficulty associated to the local measurement can be overpassed with a calibrated FE model.

The literature about prestressing in steel-concrete composite sections is abundant, but particularly test results and numerical modeling of unbonded internal tendons within the RC slab are more limited. On the one hand, in Ayyub et al. (1992a) this issue is addressed by testing a prestressed composite girder, named $E$ in the experiment, which is comprised of six unbonded internal tendons in the RC slab and subjected to a negative flexure. Therein, experimental results are compared with an analytical approach for predicting the ultimate flexural capacity of the girder (Ayyub et al. $1992 a, b)$. Acceptable matching between experimental and analytical results is then found, however no FE study was realized. In El-zohairy et al. (2017), a numerical and parametric FE study is realized in composite beams with internal and external tendons for ultimate loads. Validation with experimental results is provided for external posttensioned composite beams only, but analyses including unbonded and bonded internal tendons are not compared with experimental dataset. On the other hand, studies with bonded tendons are more commomly encountered in the specialized literature. In Ayyub et al. (1992a), also four internally prestressed steel-concrete composite girders with bonded tendons and precast slabs are tested up to ultimate loading. In Dezi et al. (1995), the viscoelastic analysis of prestressed composite beams with adhered tendon are analyzed. Particular attention is paid to the primary and secondary moment effects generated by prestressing and also to the shear force distribution at the slab-beam interface. Concrete shrinkage and cracking effects were disconsidered in that study. Later, Dezi and co-workers (Dezi et al. 1996) presented simplified and general methods for the time-dependent analysis of steel-concrete composite beams with internal bonded tendons in the RC slabs by using the finite difference method. Although shrinkage is included, concrete cracking is still dismissed. In Stojanovic and Kostic (2015) is presented a viscoelastic approach for internally prestressed steel-concrete composite beams by using the slope-deflection method. In Cao et al. (2018), the response of three prestressed steel-concrete composite continuous box beams (non-prestressed, partly prestressed and fully prestressed) are monitored for 420 days under long-term loads. The main finding of the work is that the development of the rate of deflection of prestressed beams is moderately higher than that of the nonprestressed ones, but no numerical study is carried out. In Jiang et al. (2014), an experimental research campaign is done to study the deformational behavior of steel-encased concrete composite beams with prestressed tendons. Unlike usual composite beams, the steel beam is inside the concrete element. The ANSYS software by means of a 3D FE model is used to validate the experimental dataset.

In the case of external prestressing, in El-zohairy et al. (2015) externally posttensioned composite beams are modeled with the commercial package ANSYS, therein good matching between experimental and predicted results is found for ultimate load analyses. The FE model is comprised of eight-node solid finite elements for representing the RC slab and steel beam. Connectors are modeled by coupling beam and spring elements in the axial and shear direction, respectively, whilst external tendons are modeled with commom truss elements. In Abu-Sena et al. (2018), a parametric study is performed for evaluating the effect of geometrical properties on the ultimate bending response of externally prestressed composite beams by using the commercial package ANSYS. The studied parameters include different cases of loading, tendon profiles, and different dimensions of cross sections. In Lou et al. (2016), externally prestressed steel-concrete composite beams are studied for short- and long-term loads by extending a previous planar beam model, which was initially intended for single RC beams (Lou et al. 2013). In Xue et al. (2008), the long-term behavior of an externally prestressed steel-concrete composite beam is studied under service load for one year.

Works related to unbonded internal tendon formulations in single RC elements are also found in the literature. In Lou et al. (2013), a numerical model is developed for analyzing prestressed RC beams for both service and ultimate analyses. A two-node planar beam element coupled with a straight tendon segment is hence used. It is further assumed that friction between the unbonded tendon and the duct is negligible, yielding a constant strain field over the full tendon length. This situation might correspond to a particular case derived from the approach proposed by Figueiras and Povoas (1994), in which the FE formulation of spatial unbonded curved tendons are developed based on equilibrium considerations. In Moreira et al. (2018), a two-node 2D beam element is used to model prestressed RC beams, with the complete tendon modeled by a single polygonal element crimped in a subset of beam elements. Due to lack of compatibility between the tendon and concrete, the strain in the tendon is calculated from the displacements of all associated beam elements.

Here, the present work describes a reliable 3D numerical model with material nonlinearility for the simulation of prestressed steel-concrete composite beams with internal bonded or unbonded tendons in the RC slab, or external 
tendons as well. Bonded tendons are embedded in the in the RC slab, and are totally adhered to the adjacent concrete. Otherwise, unbonded tendons may be positioned internally or externally to the RC slab. Internal unbonded tendons may slip in relation to the surrounded concrete along its entire length, whereas external tendons only slip at deviator devices located along the longitudinal direction of the steel beam. The model is based on the enhacement of a previous model called VIMIS, developed by the authors, and which have served as FE tool for other numerical studies (Tamayo et al. 2015, Dias et al. 2015, and Reginato et al. 2018). The strategy for including internal and external prestressing and some aspects of the numerical modeling of composite beams are then commented in the following sections. Emphasis is given here to the formulation of unbonded internal tendons because it represents a modification recently introduced to improve the FE model capabilities. The code is validated by comparing experimental and numerical results of several examples. In general aspects, the FE model is optimized by using shell finite elements for representing the steel beam and RC slab instead of more computational expensive solid finite elements. It has been proved that the use of shell finite elements provides accurate responses with lower requirements of memory (see e.g., Razaqpur et al. 2012, Liang et al. 2005, Sebastian and McConnel 2000, Baskar et al. 2002, Bujnak and Bouchair 2005). While the previous version is limited to the analysis of composite beams with ordinary reinforcement in the RC slab, now this is enhaced to deal with prestressing. Moreover, catenary elements can better represent curved shapes with fewer elements in relation to commom truss elements for external tendons. The model is able to capture the entire ultimate load response of continuous steel-concrete composite beams and their time-dependent behavior due to concrete creep and shrinkage for serviceability analyses. For this purpose, the short-term elastoplastic model with the long-term algorithm based on the theory of viscoelasticity are coupled (Dias et al. 2015). Concrete creep is taken into consideration using Kelvin's rheological model through a step by step time incremental procedure. Thus, a complete picture about numerical modeling of prestressed steel-concrete composite beams is delivered in this work.

\section{CONSTITUTIVE MODELING}

In the next subsections brief comments about the constitutive models used in the FE code for each part of the steel-concrete composite beam are given. For more details the reader is referred to the works of Tamayo et al. (2015), Tamayo and Awruch (2015) and Dias et al. (2015).

\subsection{RC slab, steel beam and shear connector}

The short-term concrete model is an elastoplastic one, which follows an associated flow rule with nonlinear hardening according to the uniaxial curve depicted in Figure 1(a). In the bidimensional space of principal stresses shown in Figure $1(\mathrm{~b})$, the plastic surface expands from $0,3 f_{c}$, which is considered to be the limit of the elastic state, to $f_{c}$, where $f_{c}$ is the concrete compressive strength. Thereafter, the plastic surface remains constant until finally achieve the ultimate crushing strain of concrete (0.0035). In this manner, the yield criterion is expressed by means of Equation (1).

$\sigma_{o}^{2}=0.355 \sigma_{o} \cdot\left(\sigma_{x \prime}+\sigma_{y^{\prime}}\right)+1.355\left[\left(\sigma_{x^{\prime}}^{2}+\sigma_{y^{\prime}}^{2}-\sigma_{x^{\prime}} \cdot \sigma_{y^{\prime}}\right)+3\left(\sigma_{x^{\prime} y^{\prime}}^{2}+\sigma_{x^{\prime} z^{\prime}}^{2}+\sigma_{z \prime y^{\prime}}^{2}\right)\right]$

where $\sigma_{\mathrm{o}}$ is the effective stress defined by the Madrid parabola as $\sigma_{o}=E_{c} \cdot\left(\bar{\varepsilon}_{p}+\sqrt{2 \varepsilon_{o} \bar{\varepsilon}_{p}}\right), E_{c}$ is the Young modulus, $\overline{\varepsilon_{p}}$ is the effective plastic strain based on a work hardening hypothesis and $\sigma_{i}$ with $i=x^{\prime}, y^{\prime}, z^{\prime}$ are the stress components acting at an arbitrary local system of the RC slab. This criterion is combined with a cut-off criterion for tensile stresses, i.e., concrete in tension is elastic up to it reaches its maximum tensile strength $f_{t}$. After this value, concrete cracks following its maximum principal stress direction. A maximum of two perpendicular cracks are allowed to form at each integration point. Concrete between cracks is able to resist loads, and then a tension stiffening model (softening curve in Figure 1(a)), which also account for tension softening, is used. Aggregate interlock is also considered in the cracked model (Tamayo et al. 2013a, b). For long-term analyses, the combined short-term elastoplastic model is coupled with the viscoelastic law (Dias et al. 2015). 


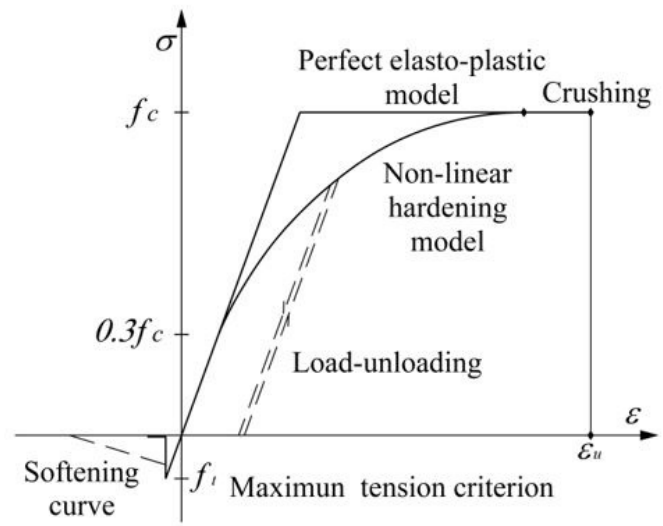

a) One-dimensional behavior

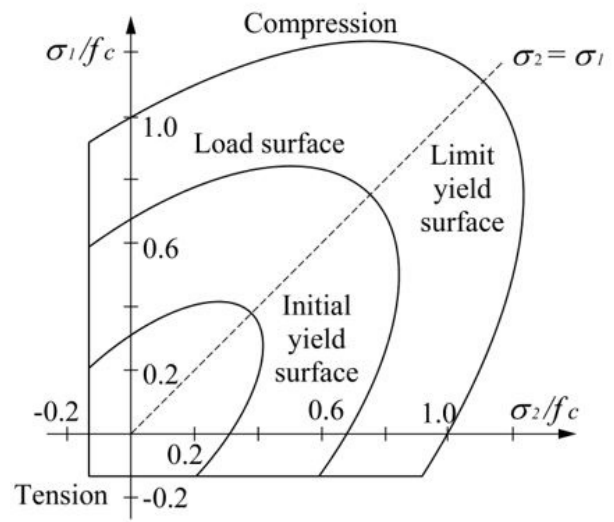

b) Two-dimensional criterion

Figure 1 Constitutive modeling of concrete.

Otherwise, the multiaxial state of stresses in the steel beam follows the commom Von Mises yield criterion as stated by Equation (2) and shown in Figure 2(a) for the bidimensional space of principal stresses.

$\sigma_{o}^{2}=\sigma_{x \prime}^{2}+\sigma_{y^{\prime}}^{2}-\sigma_{x^{\prime}} \cdot \sigma_{y^{\prime}}+3 \sigma_{x^{\prime} y^{\prime}}^{2}$

where $\sigma_{\mathrm{o}}$ is again the effective stress expressed in terms of the plane stress components $\sigma_{x \prime \prime}, \sigma_{y \prime}$ and $\sigma_{x \prime y \prime}$. A linear hardening law controlled by the uniaxial curve depicted in Figure 2(b) is futher assumed to monitor the expansion of the plastic surface. This bilinear curve also controls the uniaxial behavior of ordinary and prestressed reinforcements, in which ordinary reinforcement does not creep with time, but relaxation can be induced in the tendon by time effects. Connectors, in charge of transferring shear forces from the RC slab to the steel beam follow a nonlinear law, which relates the current shear force in the connector with the associated slip at the slab-beam interface, as shown Figure 2(c) and defined by Equation (3).

$F_{\beta}=a\left(1-e^{-b s_{\beta}}\right)$

where $F_{\beta}$ and $s_{\beta}$ are the shear force in the connector and slip at the slab-beam interface in the $\beta$ direction, respectively. When $\beta=90^{\circ}$, it refers to the shear flow acting along the longitudinal direction of the beam, $\mathrm{X}$-axis in Figure 3(a). Parameters $a, b$ define the ultimate shear force and shape of the connector curve, respectively. They are calibrated in order to match the actual stiffness of the connector encased in a RC slab portion according to $k_{\beta}=$ $a b . \exp \left(-b s_{\beta}\right)$. In this manner, concrete contribution around the connector is taken into consideration in the $\mathrm{FE}$ model. Moreover, slip is computed from the nodal displacement at the conector ends.

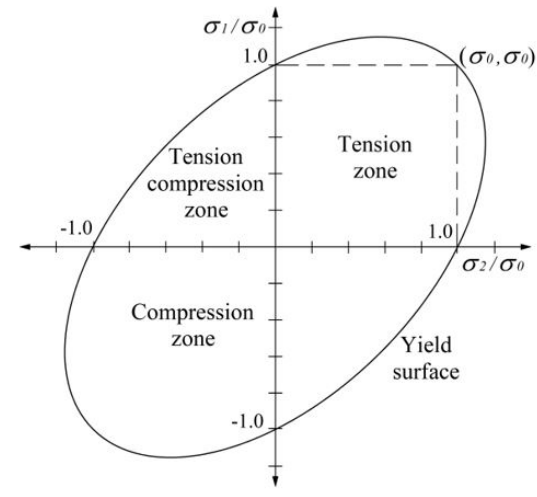

a) Von Mises yield criterion

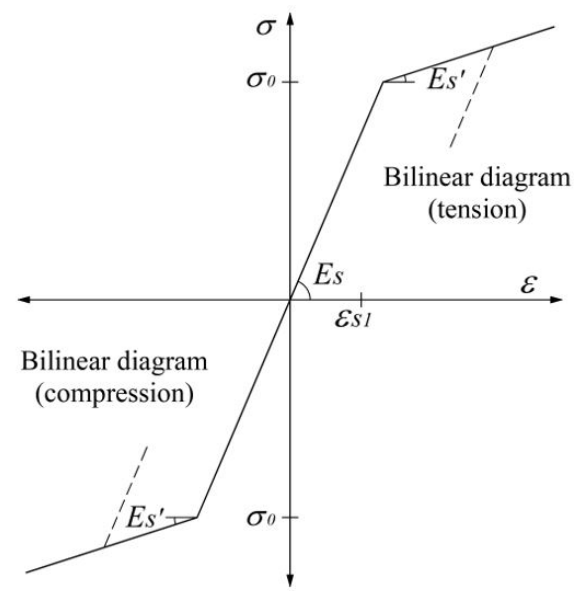

b) Bilinear uniaxial law

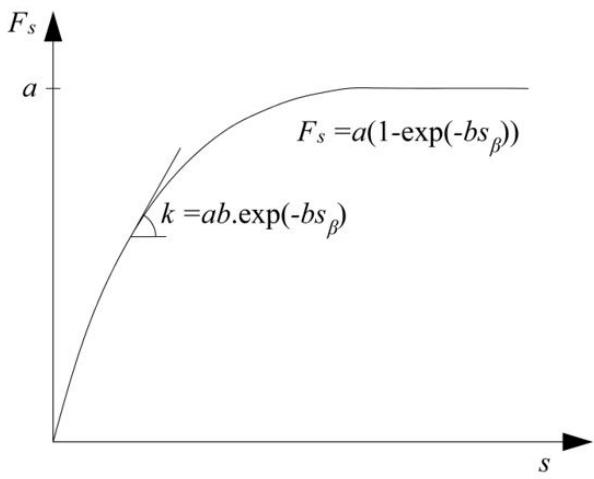

c) Shear force versus slip

Figure 2 Constitutive modeling for steel beam, reinforcement and connectors 


\subsection{Tendons}

The tension part of the uniaxial stress-strain relationship displayed in Figure 2(b) is also used as a constitutive law for internal and external tendons. The behavior at deviators locations in the case of external prestressing is simulated by using zero-length contact elements, in which slipping between the tendon and a given deviator is allowed along the longitudinal direction (in the axial direction of the tendon segment). Meanwhile, full compatibility is enforced in other directions by using high stiffness values. This release, as it will be shown later, permits obtaining a constant stress field along the tendon length, similar to that encountered in experimental results. Each contact element is composed of three mutually uncoupled perpendicular springs as shown Figure 3(a), where nodes $i$ and $j$ initially share the same nodal coordinates in the undeformed configuration of the beam. Otherwise, in the case of unbonded internal tendons, they are able to slip in relation to the surrounded concrete with some friction. For this purpose, the procedure used by Figueiras and Povoas (1994) is employed herein to compute the strains from nodal displacements. Firstly, the equilibrium condition for a generic curved tendon segment, as shown in Figure 3(b), is stated by means of Equation (4).

$d P / d s= \pm \mu \chi P_{(s)}$

where $\mu$ and $\chi$ are the friction coefficient and curvature of a tendon segment of length $d s$, while $P_{(s)}$ is the associated prestressed force in the tendon at a generic section $s$. The sign of the equation depends upon the relative movement between the tendon and the sheathing. The solution of the differential equation allows expressing the tendon strain by means of Equation (5) (see Figueiras and Povoas 1994).

$\Delta \varepsilon_{p}=\Delta \varepsilon_{p, m} \cdot e^{\int_{s_{A}}^{s} \pm \mu \chi d s} / E_{p(s)}$

with,

$\Delta \varepsilon_{p, m}=e^{\int_{l p} \Delta \varepsilon_{c, p} d s}$

where $E_{p(s)}$ is the Young modulus of the prestressed steel, $\Delta \varepsilon_{p}$ is the increment of strain in the unbonded tendon, $\Delta \varepsilon_{c, p}$ is the strain increment in the concrete fiber next to the tendon, and $\Delta \varepsilon_{p . m}$ is the average strain increment in the tendon acting along its length. The integrals appearing in Equations (5) and (6) refer to tendon section $s_{A}$, which corresponds to the anchorage end $A$, in which the prestressed force is applied, meanwhile $s$ refers to a generic section along the tendon length $l_{p}$ (see Figure $3(c)$ ). For the particular case when $\chi=0$, i.e., when the tendon is straight, as commonly occurs in RC slabs of composite sections, or when $\mu=0$ (i.e., fully unbonded), the strain increment is uniform along the tendon length, $\Delta \varepsilon_{p}=\Delta \varepsilon_{p, m}$. After, $\Delta \varepsilon_{p}$, is computed from Equation (5), the stress increment, $\Delta \sigma_{p}$, is obtained from the current total strain by using the strain-stress relationship shown in Figure 2(b). Therefore, the current stress in the tendon for short-term loads is evaluated by means of Equation (7).

$\sigma_{p}=\sigma_{p}^{o}+\Delta \sigma_{p}$

with $\sigma_{p}^{o}$ being the previous stress in the tendon. For time effects, the prestress loss increment $\Delta \sigma_{p t, r}$ due to steel relaxation must be added to the right hand side of Equation (7). This quantity is computed based on the tendon yield strength $f_{p y}$, kind of steel relaxation and time interval, $t$, of interest. The time is measured in hours from the instant at which the initial prestress, $\sigma_{p o}$, is applied. A factor $k$ equal to 10 and 45 is assigned for steels with normal and low relaxation, respectively.

$\Delta \sigma_{p t, r}=-\frac{\sigma_{p o}}{k}\left[\log _{10} t\left(\frac{\sigma_{p o}}{f_{p y}}-0.55\right)\right]$

\section{FINITE ELEMENT FORMULATIONS}

A three-dimensional nonlinear FE model using the in-house code VIMIS is used for the studied examples. A detailed explanation of each part that composes the steel-concrete composite beam is presented in the following 
sections. More details can be found in Tamayo et al. (2015) for the RC slab, steel beam and shear connector, meanwhile the reader is refered to the work of Figueiras and Povoas (1994) for the internal tendon element formulation.

\subsection{RC slab, steel beam and shear connector}

Three-dimensional shell elements with eight nodes are used to represent the middle plane of the RC slab. The slab element is composed of several layers through its thickness in order to properly capture nonlinear variation due to concrete behavior. Additional smeared layers are also defined to represent steel reinforcement as shown in Figure 4(a). The element presents five degrees of freedom at each node with three translation and two in-plane rotations. The FE mesh is established in order to properly capture cracking and crushing at monitored points. Otherwise, the mid-planes of the steel beam, i.e., flanges and web are modeled with four-noded thin shell elements. This element results from the assemblage of a thin plate element with a membrane element with drilling degree of freedom, resulting in an element with six degrees of freedom at each node as displayed in Figure 4(b). The element is able to detect plastic zones by using five integration points through its thickness.

Shear connectors are modeled by means of two-node beam-colum elements as represented in Figure 5, which joint the middle plane of the RC slab with the adjancent middle plane of the upper steel flange at discrete locations, according to the spacing of connectors in the real project. Then, a gap equal to the sum of half slab thickness plus half top flange thickness exists between the slab and the top steel flange of the beam.

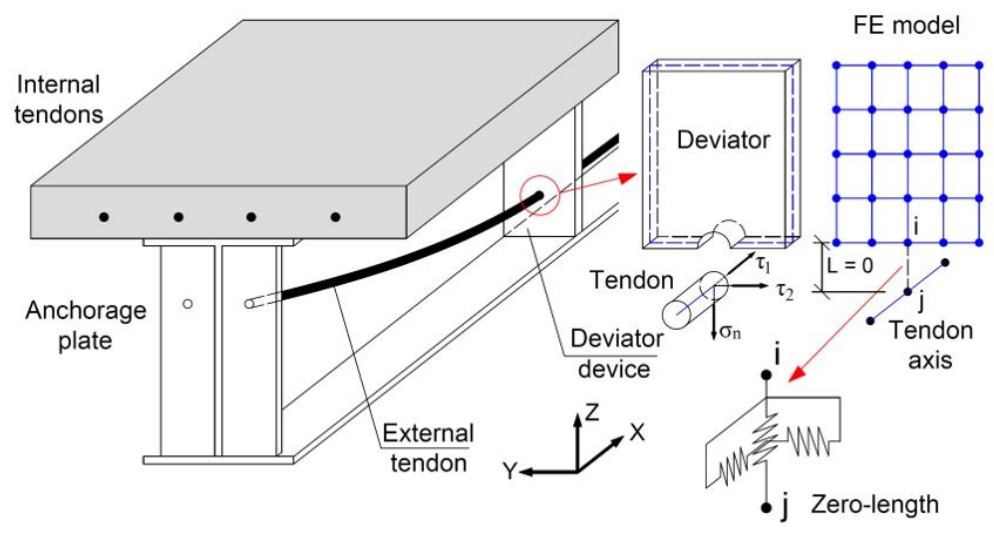

a) Springs at deviator

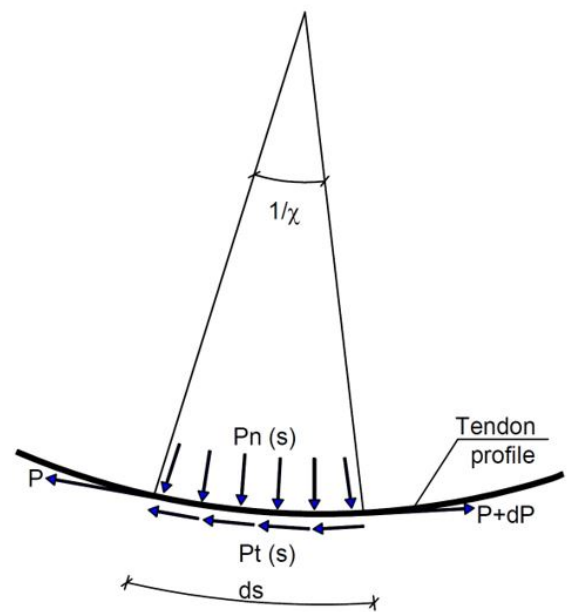

b) forces in curved tendon segment

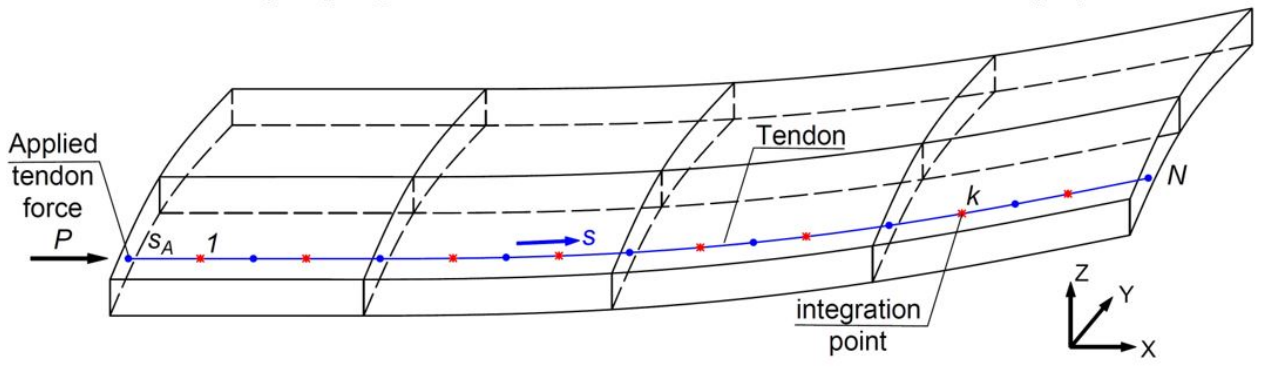

c) Geometry of the prestressed tendon

Figure 3 Elements used for external and internal prestressing.

Therefore, the beam-column element of length equal to this gap joints adjancent nodes of the middle-plane of the slab and the top steel flange. This element accommodates nonlinearility along their longitudinal and transversal shear directions according to Equation (3). Based on the kinematics of the shear connector between two successive load increments $n$ and $n+1$, and for three connectors along the beam axis as depicted in Figure 6 , the assumptions established in the work of Bujnak and Bouchair (2005) are considered in this study. The complete stiffness fomulation of the connector element can be found in Tamayo et al. (2015). 
- It is assumed that $v_{c}^{m}=v_{s}^{m}$, i.e., there is no uplift between the slab and steel beam, where superscript $m$ refers to the central connector in Figure 6 and subscripts $c$ and $s$ refer to the concrete slab and steel beam, respectively. This compatibility is obtained by using a high axial stiffness in the longitudinal direction of the connector.

- It is assumed that $\theta_{c}^{m}=\theta_{s}^{m}$, i.e., compatibility of rotations is forced in adjacent nodes based on the assumption that the beam section remains plane after deformation. This is done by imposing equal rotations on nodes for slab and steel beam.

- The horizontal displacement in each node of the slab with an adjancent connector is computed as the sum of the displacement of the corresponding node on the top steel flange increased by the relative slip in the connector, i.e., $u_{c}^{m}=u_{s}^{m}+s^{m}$, where the current total slip $s^{m}$ is computed from the constitutive law shown in Figure 2(c). Also, a secant version may be used $s_{n}^{m}=F\left(s_{n}^{m}\right) / k_{n}^{m}$, where $k_{n}^{m}$ is the current secant stiffness of the connector.

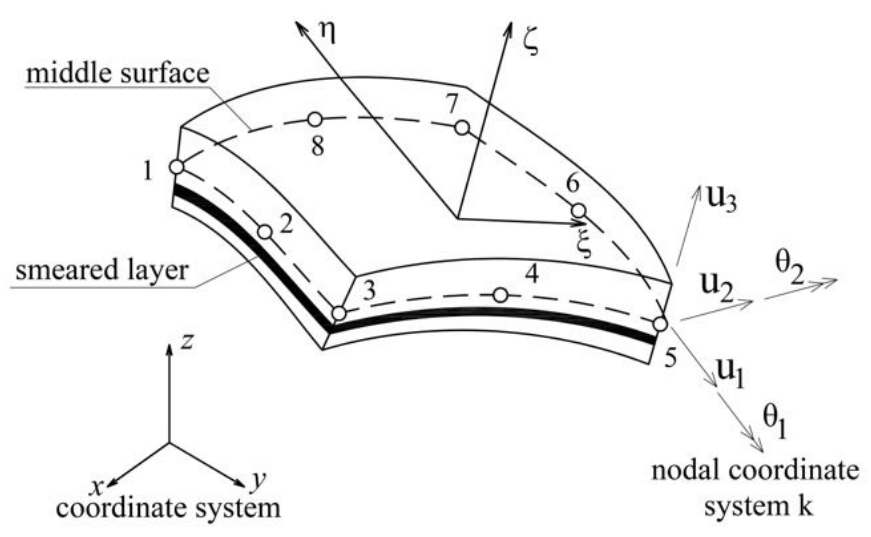

a) Layered thick shell finite element for RC slab

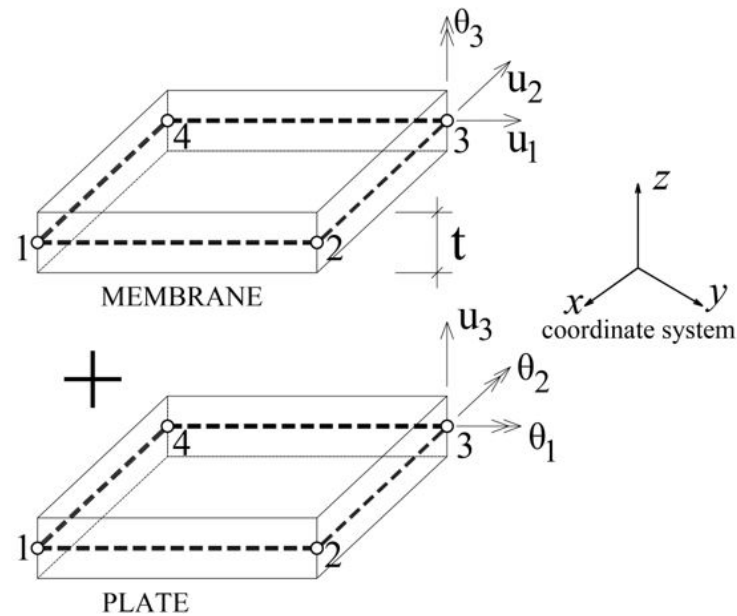

b) Thin-shell element for steel beam

Figure 4 Finite element for RC slab and steel beam.

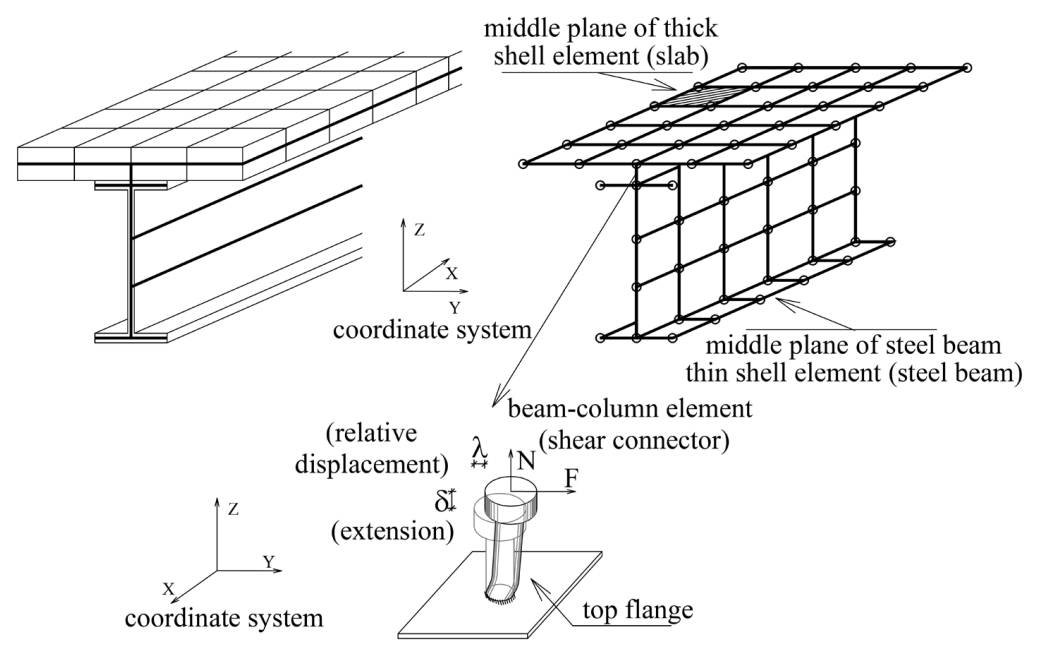

Figure 5 Connector detail and composite beam modeling. 


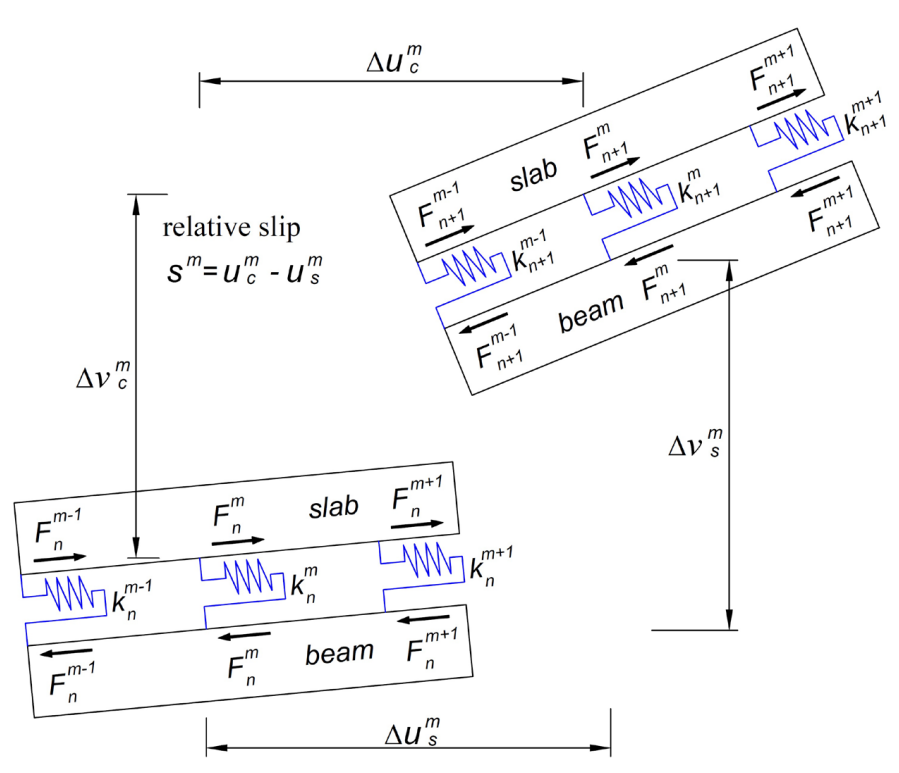

Figure 6 Kinematic assumptions for the shear connection (Bujnak and Bouchair 2005).

\subsection{Tendons}

External tendons are modeled using 3D catenary elements as displayed in Figure 7(a), which are accurate because the equilibrium position of a hanging catenary is intrinsic, while they better match curved forms with fewer elements in relation to commom truss elements. Furthermore, this element is appropriate for flexible cables subjected to selfweight loads, and its complete FE formulation can be found elsewhere (Coarita and Flores 2015). The external tendons behave similarly to internally unbonded tendons with full compatibility at anchorage zones, whereas they are attached at discrete locations to deviator devices along its length (Moscoso et al. 2017). At the anchorage zone, the catenary and shell elements representing the tendon and plate, respectively, share the same node in the FE model.

Otherwise, internal bonded or unbonded tendons are simulated by one-dimensional curved elements embedded in the RC slab as shown in Figure 3(c). The algorithm for computing the incremental strain $\Delta \varepsilon_{p}$ stated in Equation (5) follows the numerical integration presented in the work of Figueiras and Povoas (1994). The method initiates at the anchorage end, designated as section $A$, and takes in sequence the integration points of all tendon segments. The procedure is explained in the following lines.

1. Calculate the strain in concrete $\Delta \varepsilon_{c, p}$.

Compute the increment of strain in concrete at the tendon level $\Delta \varepsilon_{c, p}=B_{p} . \Delta d$, in which $B_{p}$ is the commom strain-displacement matrix of a curved tendon segment at the current integration point, and $\Delta d$ is the incremental displacement vector of nodal variables of the slab finite element, in which the current tendon segment is embedded. Calculate $\Delta \varepsilon_{c, p}$ at each integration point and find the variation in length of the tendon with the following equation.

$\Delta l_{p}=\sum_{k=1}^{N}\left(\Delta \varepsilon_{c, p}\right)_{k} \cdot v_{k} \cdot w_{k}$

where $N$ is the number of integration points along the tendon, $v_{k}$ is the norm of a vector tangent to the tendon at the integration point $k$, and $w_{k}$ is the associated weight of integration. If the tendon is straight, $v_{k}$ adopts a unit value. It is important to mention that a tendon element is formed by various tendon segments along its length. Then, Equation (9) is applied to each tendon embedded in the RC slab.

2. Next, shape function $g\left(s_{k}\right)$ is calculated.

$g\left(s_{k}\right)=g_{k}=\frac{1}{\left(E_{p}\right)_{k}} \prod_{j=1}^{k} e^{ \pm \mu \chi_{j} v_{j} w_{j}}$

with the sign of the coefficient of friction $\mu$ defined by means of Equations (11)-(12), where the superscript $i$ represents the iteration number within the iteration loop of the commom nonlinear Newton-Raphson process, meanwhile subscript $j$ varies from 1 to $k$ (e.g., Figure 3(c)): 
iteration 1: $\left(\Delta \varepsilon_{c, p}\right)_{j}^{1}-\left(\Delta \varepsilon_{c, p}\right)_{j-1}^{1}\left\{\begin{array}{c}>0 \rightarrow \text { positive sign } \\ <0 \rightarrow \text { negative sign } \\ =0 \rightarrow \mu=0\end{array}\right.$

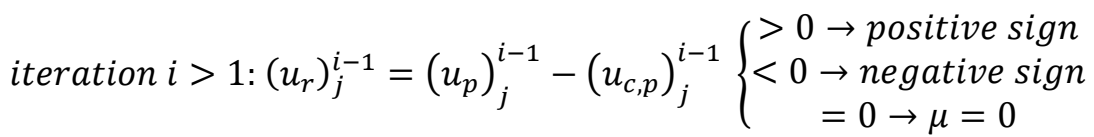

where $u_{p}$ and $u_{c}$ are the accumulated elongation of the tendon and that of the concrete fiber next to it, respectively, measured from section $s_{A}$. In this manner, the relative movement, $u_{r}=u_{p}-u_{c}$, is introduced, and the corresponding sign of the friction coefficient is then defined. Precisely, in Figure $7(b)$ is shown the correlation between the sign of $\mu$ and $u_{r}$

$u_{p}(\mathrm{~s})=\int_{s_{A}}^{s} \Delta \varepsilon_{p}(s) d s$

$u_{c, p}(\mathrm{~s})=\int_{s_{A}}^{s} \Delta \varepsilon_{c, p}(s) d s$

3. Evaluate the integral,

$\int_{l_{p}} g(\mathrm{~s}) d s=\sum_{k=1}^{N} \frac{v_{k} w_{k}}{\left(E_{p}\right)_{k}} \prod_{j=1}^{k} e^{ \pm \mu \chi_{j} v_{j} w_{j}}\left(\equiv \sum g_{k} v_{k} w_{k}\right)$

4. Finally, the strain increment of Equation (5) is expressed by:

$\left(\Delta \varepsilon_{p}\right)_{k}=g_{k} \cdot \frac{\Delta l_{p}}{\sum g_{k} v_{k} w_{k}}$

The strain increment in the above equation is then used to evaluate the tendon stress increment $\left(\Delta \sigma_{p}\right)_{k}$ according to the bilinear law shown in Figure 2(b). The aforementioned procedure has been successfully adopted in single RC elements by Figueiras and Povoas (1994) and Fabregat (1988), and now it is used for prestressed slabs in composite beams. The procedure iterates following the iteration loop of the well-known Newton-Rapshon method, until finally achieved the equilibrion condition for the current load increment. The assemblage of all above-mentioned finite elements was schematically depicted in Figure 5, and now the commonly resulting FE mesh together with boundary conditions used in VIMIS are shown in Figure 7(c). In the next sections, a null friction coefficient is used to model fully unbonded behavior as described in the corresponding experimental reports of the given examples. Furthermore, the tendon stiffness contribution of unbonded tendons is included in the analysis for both numerical stability and speed of convergence of the nonlinear algorithm. This issue is verified in the incoming examples.

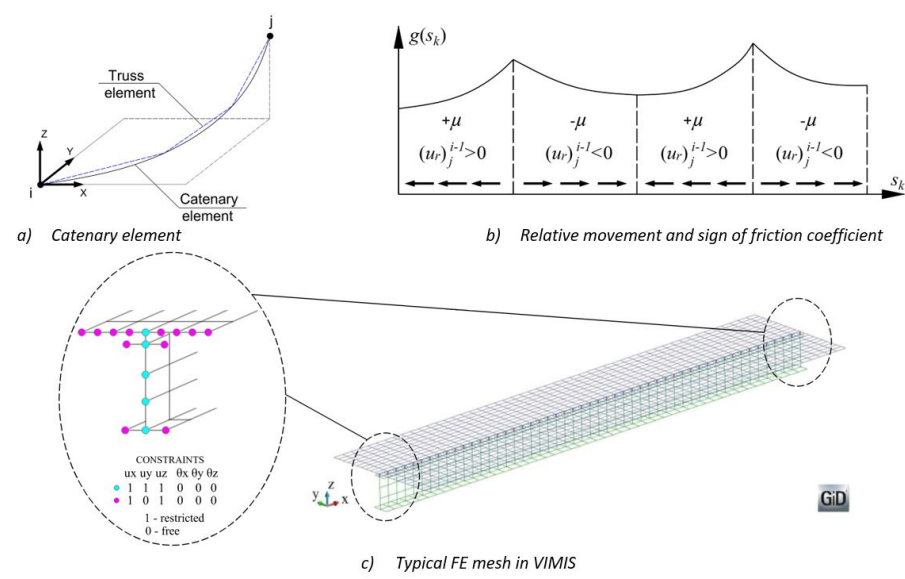

Figure 7 Catenary element, slipping at tendon-concrete interface and FE mesh in VIMIS. 


\section{APPLICATIONS}

This section presents various examples in which the proposed FE model corroborates varios test results from RC and steel-concrete beam specimens. The complete input data of all examples may be obtained in the quoted references. Comparison is made between numerical predictions and experimental data whenever is possible. Emphasis is given to the evaluation of prestresed forces in the tendons.

\subsection{Prestressed beams tested by Guo et al. (2018) and Tao and Du (1985)}

Two prestressed beams with fully unbonded tendons are analyzed in this section. Firstly, beam designated as PC2 tested by Guo et al. (2018), is selected to monitor time dependent prestress losses in the tendon for one year. The curved tendon and beam geometry are displayed in Figure 8. Cubic compressive strength of concrete is $55 \mathrm{MPa}$. Ordinary steel bars of $12 \mathrm{~mm}$ in diameter with steel reinforcement ratio of $0.94 \%$, and yield strength of $335 \mathrm{MPa}$ are used in the beam. The initial prestress force of $103.9 \mathrm{kN}$ is applied at one-end by means of a load cell at 30 days after concrete casting. Immediately after, two point loads of $3.125 \mathrm{kN}$ are applied as a secondary dead load at one-third and two-third points of the span. The tendon has a nominal tensile strength of $1860 \mathrm{MPa}$ and cross section area of $140 \mathrm{~mm}^{2}$.

The second studied beam, designated as A1, is tested by Tao and Du (1985) for ultimate load analysis. This beam is also simply supported and subjected to two point loads as shown in Figure 9. Concrete compressive strength is 30.6 MPa, yield strength of ordinary reinforcement is $267 \mathrm{MPa}$, concrete crushing strain is 0.0025 , and yield and ultimate strengths of the prestressed steel are $1465 \mathrm{MPa}$ and $1790 \mathrm{MPa}$, respectively. The applied initial prestress is $960 \mathrm{MPa}$ for a tendon area of $58.8 \mathrm{~mm}^{2}$. The beam has a bottom reinforcing steel area of $157 \mathrm{~mm}^{2}$.

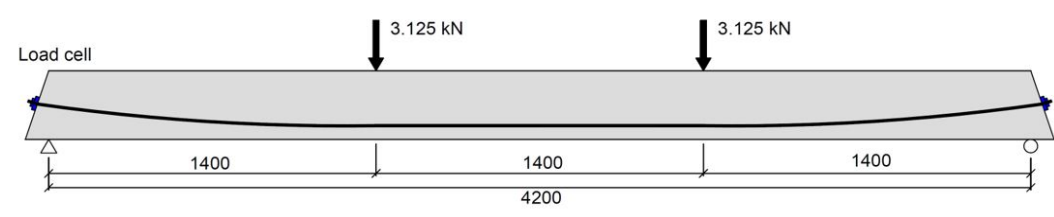

a) Longitudinal direction

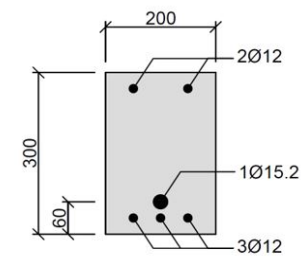

b) Cross-section

Figure 8 Geometry and loading of beam PC2 with curved tendon tested by Guo et al. (2018). [Units: mm]

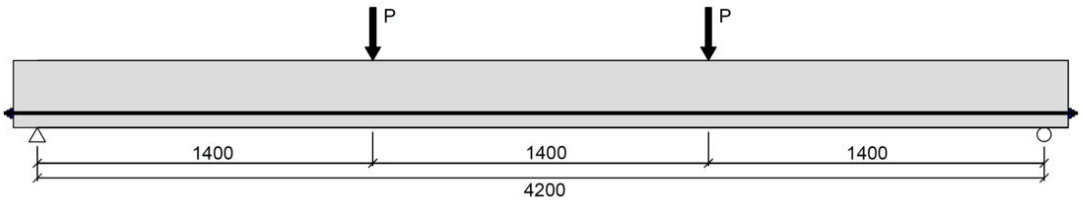

a) Longitudinal direction

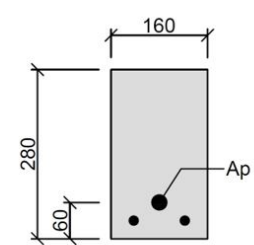

b) Cross-section

Figure 9 Geometry and loading of beam A1 with straight tendon tested by Tao and Du (1985). [Units: mm]

In Figure 10(a) is depicted the prestress loss evolution after jacking for beam PC2 measured at the load cell. As it may be observed, the prestress loss predicted by the FE model slightly underestimates the experimental result with time, but the stress tendency is well established. The predicted final prestress loss is $48 \mathrm{MPa}$, which represents $6.5 \%$ of the initial applied stress; meanwhile this is $53.9 \mathrm{kN}(7,3 \%)$ in the experiment. Furthermore, the prestress loss predicted according to the formula of the Brazilian Regulation NBR 6118 (2014), which is initially intended for bonded tendons, unexpectantly yielded a closer value of $54.7 \mathrm{MPa}(7,4 \%)$. Moreover, in Figure 10(b) is depicted the prestres loss evolution along the beam axis. As it can be seen, the experimental prestress loss is higher at the beam ends while it decreases at midspan. Because the tendon is fully unbonded, the numerical model predicts a constant stress field along the tendon length. Reliability studies due to material uncertainties carried out by Chen and Zhang (2018) have demonstrated that the prestress loss in simply supported RC beams can vary substantially in relation to its average value. Hence, the provided FE predictions are in the range of these expected values.

Otherwise, in Figure 11(a) is displayed the load-deflection curve at midspan for the prestressed beam A1 with straight tendon. As it may be observed, the load capacity of the beam agrees well with the experimental results at various load levels. Figure 11(b) shows the stress evolution in the tendon as loading is increased in the beam. As it may 
be observed, favourable agreement is also encountered. In Figure 11(c) is displayed the stress tendon evolution with deflection. The ultimate stress value is attained, but the predicted stress path is elastoplastic because a bilinear stressstrain relationship was adopted for the prestressed steel. It is believed that using a multilinear stress-strain relationship would better match the curved experimental stress path. Figure 12(a) depicts the longitudinal normal stresses acting at the upper concrete layer over beam half-span. As expected, the blue zone, which is located between the midspan and a point load, presents the higher compressive stresses. Indeed, the maximum predicted stress is $3.26 \mathrm{kN} / \mathrm{cm}^{2}$, which is slightly higher than the concrete compressive strength of $3.06 \mathrm{kN} / \mathrm{cm}^{2}$. This behavior is verified and illustrated in Figure 12(b) by comparing the experimental and predicted concrete patterns. As it can be seen, cracking spreads from the central region of the beam to the supports from the bottom to the upper layers. Meanwhile, the central region of the upper layer is fully crushed, i.e., concrete losses its rigidity and load resistance capacity, finishing with the overall failure of the beam. Furthermore, a better rate of convergence is attained when the tendon stiffness is included in the numerical analysis

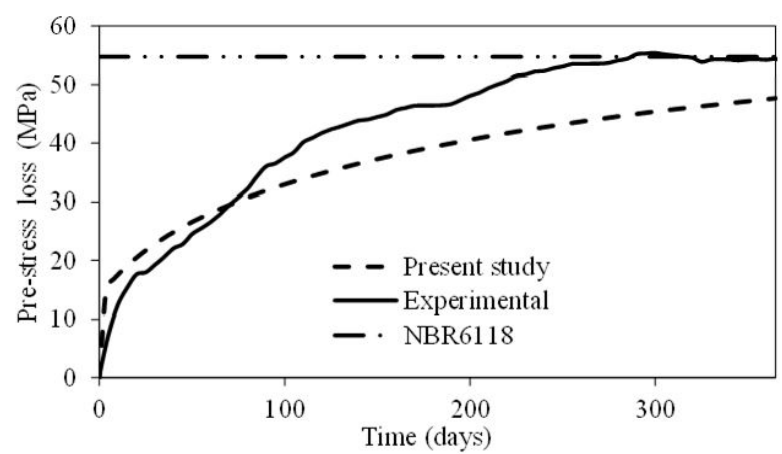

a) Prestressed loss evolution

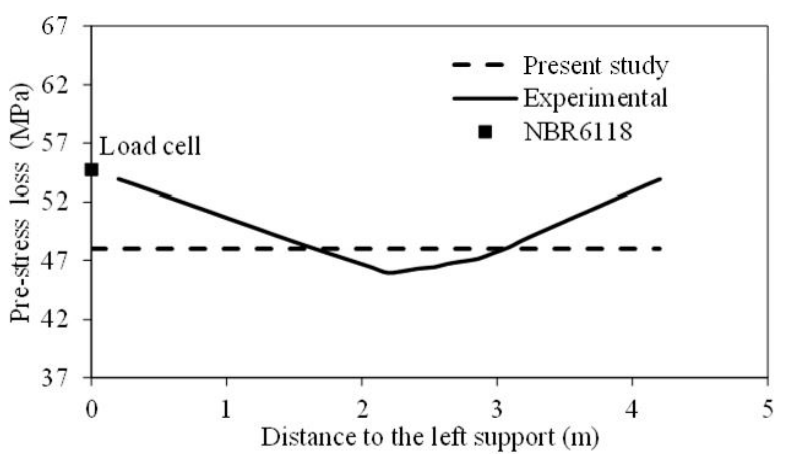

b) Prestressed losses along beam span

Figure 10 Results of unbonded prestressed beam PC2.

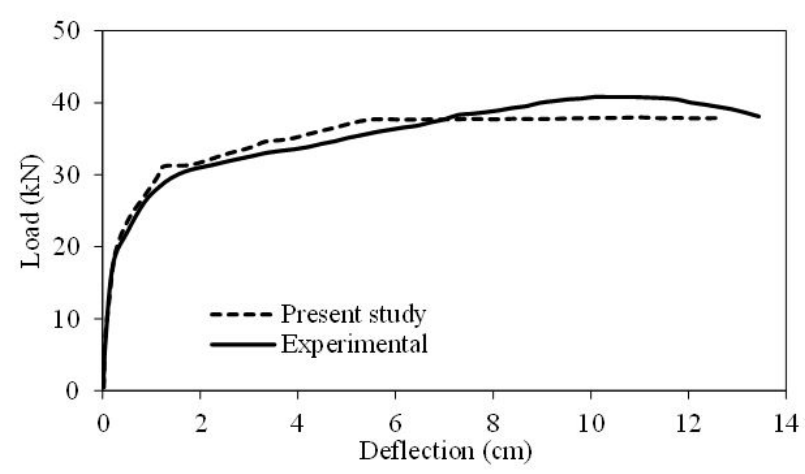

a) Load-deflection curve at midspan

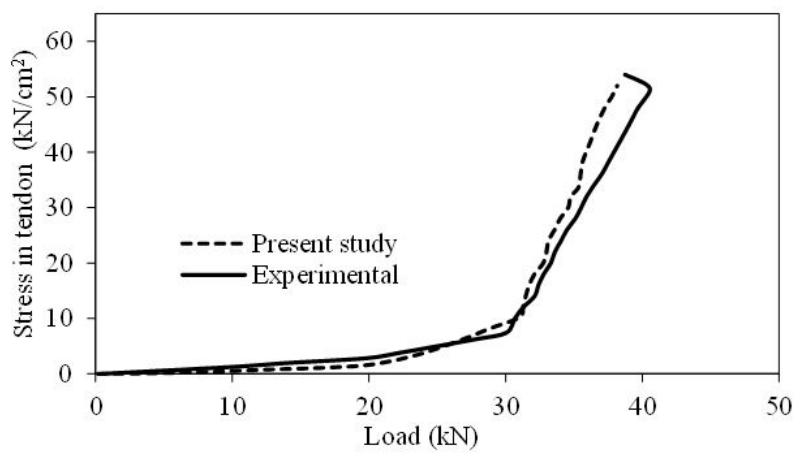

b) Evolution of stress in the tendon

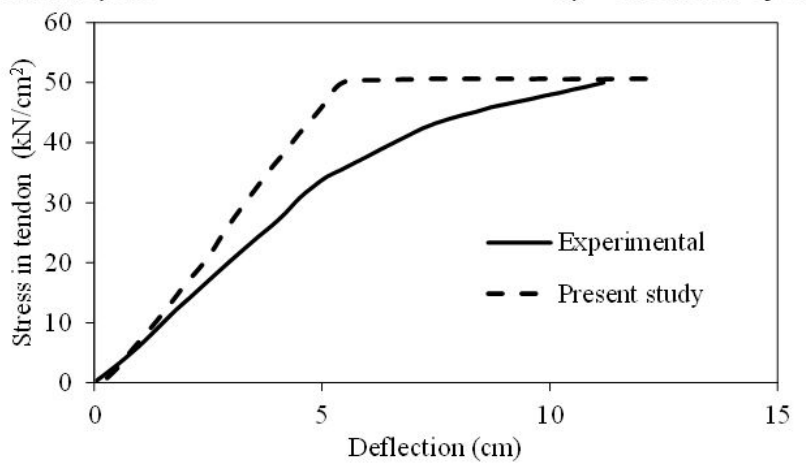

c) Stress in tendon with deflection

Figure 11 Results of unbonded prestressed beam A1. 


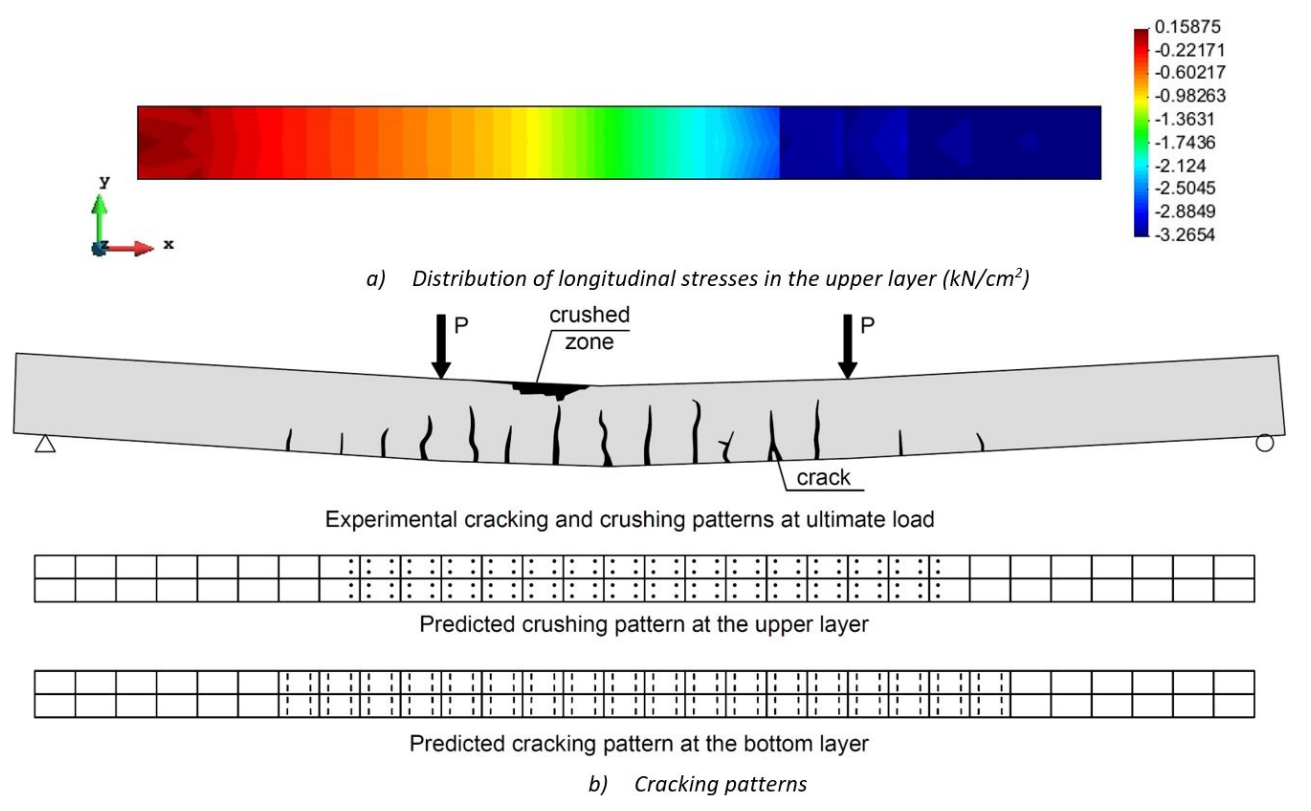

Figure 12 Stresses and cracking patterns for beam A1.

\subsection{Long-term analysis of steel-concrete composite beam studied by Dezi et al. (1996)}

The two-span steel-concrete composite beam shown in Figure 13 is studied in Dezi et al. (1996) for long-term loads. The effects of three applied actions, namely uniformly distributed load of $64.56 \mathrm{kN} / \mathrm{m}$, concrete shrinkage and prestressed force applied to the slab, are evaluated separately in that work. The cross section area of the tendon is $3058 \mathrm{~mm}^{2}$, with a bonded tendon length of $20 \mathrm{~m}$ over the interior support, together with a prestressed force of $4000 \mathrm{kN}$. Concrete compressive strength is $30 \mathrm{MPa}$, shear connection stiffness is $0.5 \mathrm{kN} / \mathrm{mm}^{2}$ and relative humidity at which the concrete slab was exposured is $50 \%$. All actions are applied at 30 days after concrete casting with shrinkage starting at 7 days. The analysis time is 70 years and the model code CEB-FIP 90 is used for the time-dependent behavior.

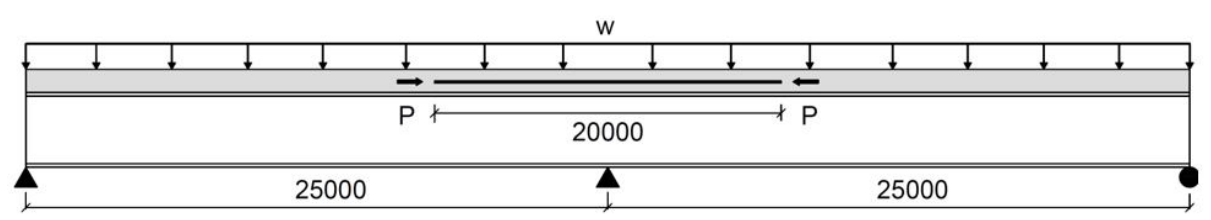

a) Longitudinal direction

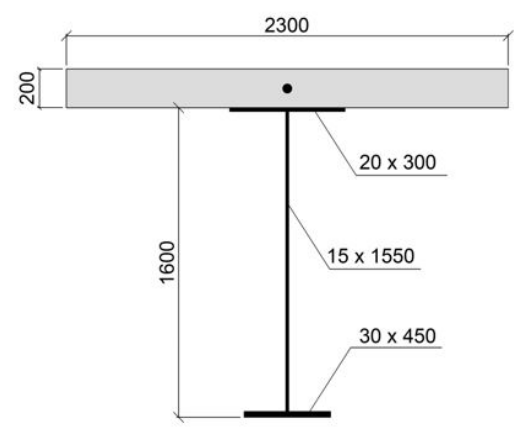

b) Cross-section

Figure 13 Geometry and loading of two-span composite beam studied by Dezi et al. (1996). [Units, mm]

In Figures 14(a)-(b) are depicted the final deflections along the beam axis due to concrete creep and shrinkage for 70 years of sustained load, respectively. As it may be observed, present results compared favourably with Dezi et al.'s ones, in which the finite difference method is used for the spatial and temporal discretization of the composite beam. In Figures 15(a)-(b) are displayed the effect of prestressing upon beam deflexion and tendon force evolution at the end of the analysis. Also, good agreement is encountered at all sections and times. The prestressed force diminishes from $4000 \mathrm{kN}$ to $3900 \mathrm{kN}$, implying a prestress loss of $2.5 \%$ after 70 years. In Figure 15(c) is displayed the evolution of the reaction at the interior support with time. The present results are compared to Dezi et al.'s ones, in which method (A) refers to a general method previously used in Figures 15(a)-(b), while method (C) is a simplified algebraic method named Effective Modulus (EM). As it may be observed, the tendency of the reaction is well captured at all times with an initial value of $110.8 \mathrm{kN}$ at 30 days. It is important to mention that Dezi et al.'s model due to its one-dimentional 
behavior is not able to capture the shear-lag effect. Also, the number of tendons used in the analysis can have a meaningful influence in the final shape of the deflected curves. This is because in Dezi et al.'s model the prestressed force is applied in one tendon along the slab axis. Optionally, in the current FE model, this prestressed force might be applied uniformly in varios tendon elements along the transversal direction of the slab. To better match Dezi et al.'s results, merely one tendon was used in the FE model. It is important to highlight that all the aforementioned effects act together and they cannot be isolated in reality. Although for the current example superposition can be invoked without incurring in too much error.

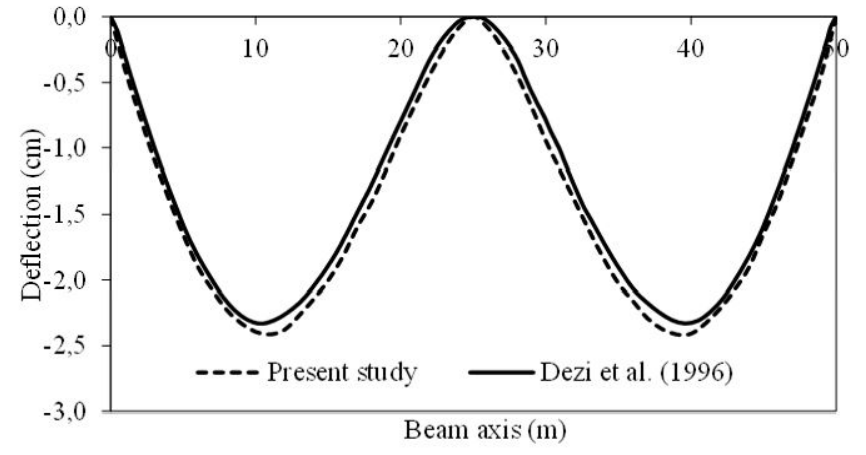

a) Only creep

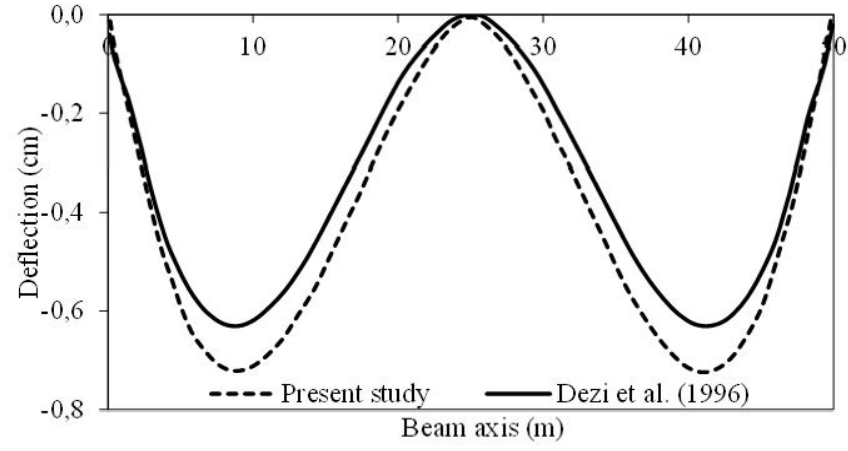

b) Only shrinkage

Figure 14 Deflexion along beam spans after 70 years.

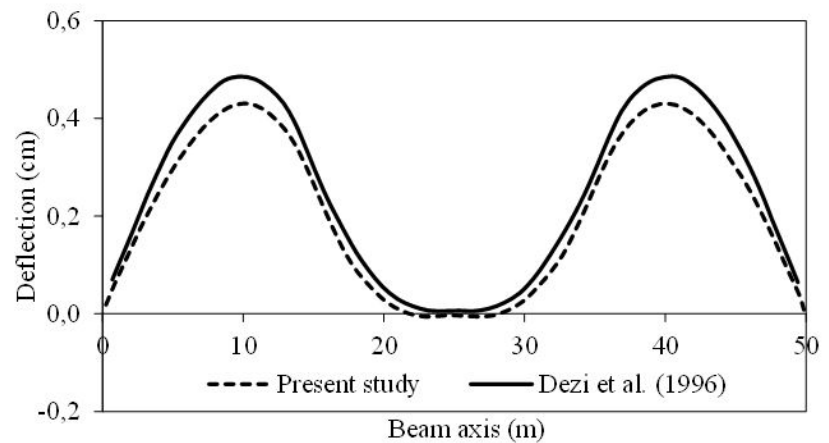

a) Only prestressing

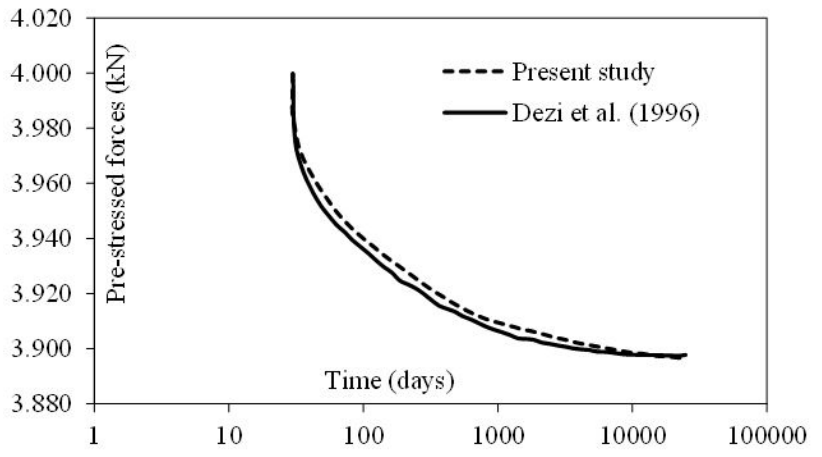

b) Tendon force evolution

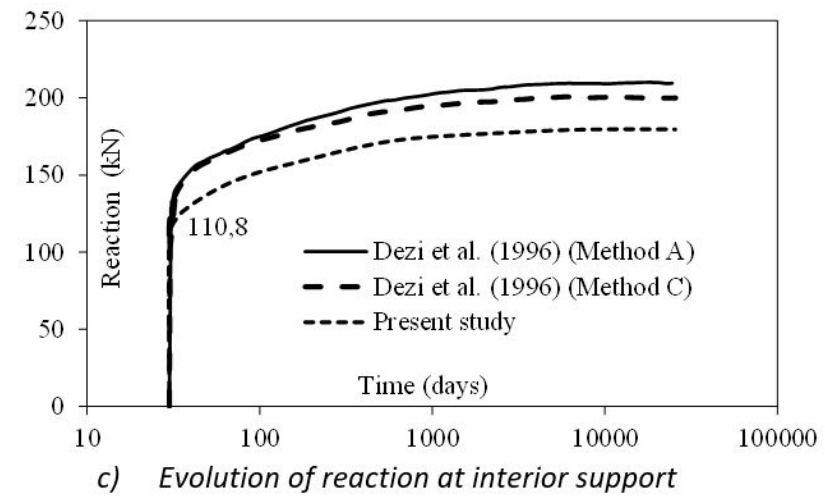

Figure 15 Final values of deflection, tendon force and reaction after 70 years.

\subsection{Short-term analysis of steel-concrete composite beam tested by Ayyub et al. (1992a)}

The girder named E tested in Ayyub et al. (1992a), which has a posttensioned cast in-place slab with unbonded internal tendons, is selected here for study. The girder is simply supported and posttensioned with six $15.2 \mathrm{~mm}$ diameter, grade 270 low-relaxation seven-wire strands. Additionally two $10 \mathrm{~mm}$ diameter longitudinal reinforcing bars and 24 transverse $10 \mathrm{~mm}$ diameter bars are placed in the slab. The girder is subjected to a midspan load and tested upsidedown to simulate tensile stresses at the concrete slab as depicted in Figure 16. Stiffners are located at the beam ends, midspan and in between every $66 \mathrm{~cm}$. Stud shear connectors are $16 \mathrm{~mm}$ in diameter, $63 \mathrm{~mm}$ in height and 
spaced in groups of four every $35 \mathrm{~cm}$. The span of the beam is laterally supported to avoid lateral-torsional buckling. Loading is applied in two stages; firstly a prestressed force of $124 \mathrm{kN}$ is applied at each tendon together with the dead load of the beam. Then, a point load is gradually exerted at midspan until failure. Material properties are reported in Ayyub et al. (1992a).

In Figure 17 is displayed the force-deflection curve of the girder at various load levels at midspan. The tested girder failed by buckling of the noncompact compression flange (upper part of the girder at midpan), and the postbuckling prediction is not stable, i.e., the load-deflection curve begins to decline as partially shown in the figure (Ayyub et al. 1992a). Then, its maximum resisting load is nearly the yield load. The predicted load-deflection curve by the FE model, which is based on the nonlinear material response only, correlates well with the measured data at all load levels before local buckling took place. This prediction also partially agrees with the analytical approach presented in Ayyud et al. 1992(b). The cracking load at which the first crack occurs according to Ayyub et al.'s analytical model is $590 \mathrm{kN}$, while this is $490 \mathrm{kN}$ for the FE model. The yield load, which corresponds to the first yielding of any component of the girder cross section, is $700 \mathrm{kN}$ for the analytical approach and $665 \mathrm{kN}$ for the FE model. The ultimate experimental and numerical loads are virtually the same (700 kN), but a higher ultimate load is forecasted by the analytical approach $(955 \mathrm{kN})$. It is important to establish that the analytical approach is based on equilibrium considerations in the cross section, but it is not able to detect local buckling failure. Although the tendons are totally unbonded, the inclusion of their stiffnesses is crucial for the numerical convergence of the nonlinear algorithm.

To shown futher results, Figures 18(a)-(b) depict the slipping at the slab-beam interface along the span at ultimate load and immediately after pretressing is applied, respectively. As it may be observed, close to the beam ends the slip curve is nearly horizontal acting with their maximum absolute values at these locations, whereas the inflection point with null slip occurs at the point load section. The reported ultimate experimental slip at the beam end is $0.3 \mathrm{~mm}$, while this is $0.8 \mathrm{~mm}$ for the FE model.

In Fig. 19 is illustrated the Von Misses stresses in the steel beam at ultimate yield load of $700 \mathrm{kN}$. As it can be seen, the upper part of the beam at midspan is highly compressed with a maximum stress value of $45.7 \mathrm{kN} / \mathrm{cm}^{2}$, which is higher than the yield strength of the steel beam $\left(38.9 \mathrm{kN} / \mathrm{cm}^{2}\right)$ due to linear hardening of the material. Because of this stress concentration, local buckling is plausible at midspan, but the FE model is not able to detect it. Instead it predicts the yield load and the algorithm is not able to achieve convergence.
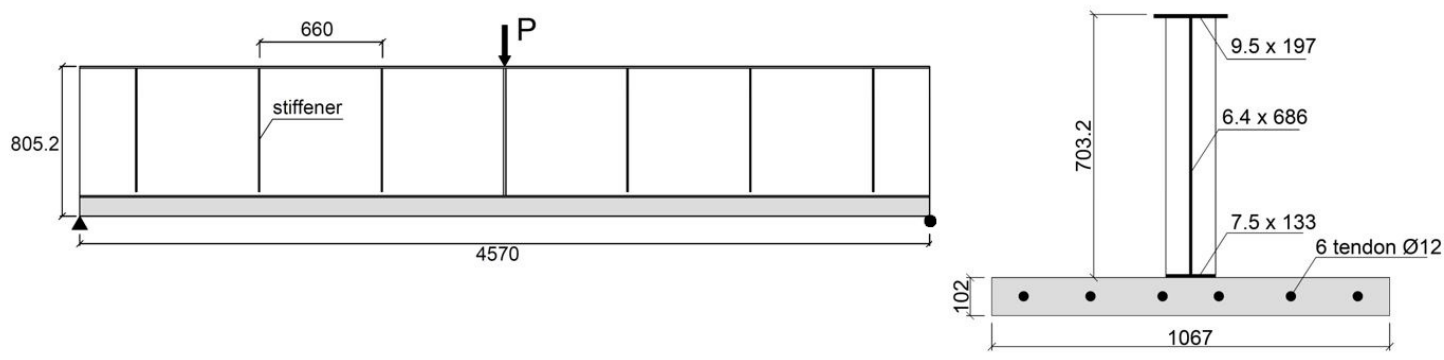

a) Longitudinal direction

b) Cross-section

Figure 16 Geometry and loading of composite beam tested by Ayyub et al. (1992a). [Units, mm]

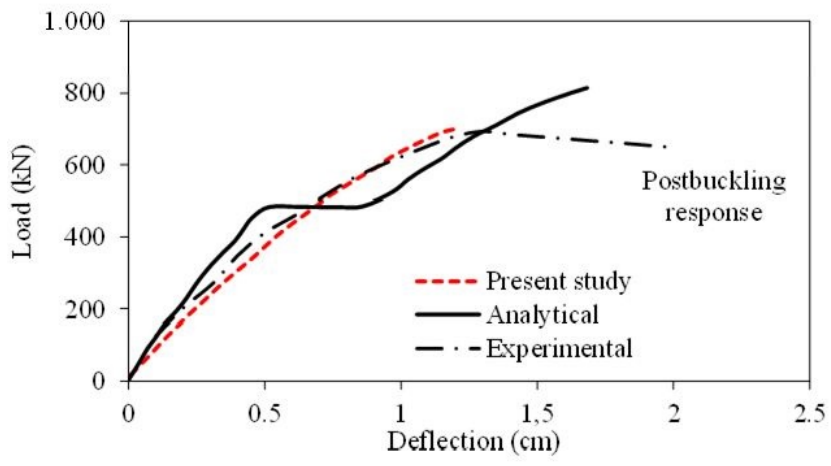

Figure 17 Load-deflection curve at midspan. 


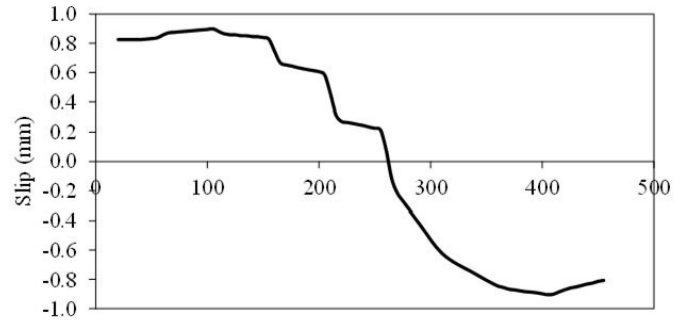

Distance to the left support $(\mathrm{cm})$

a) Slip at ultimate load

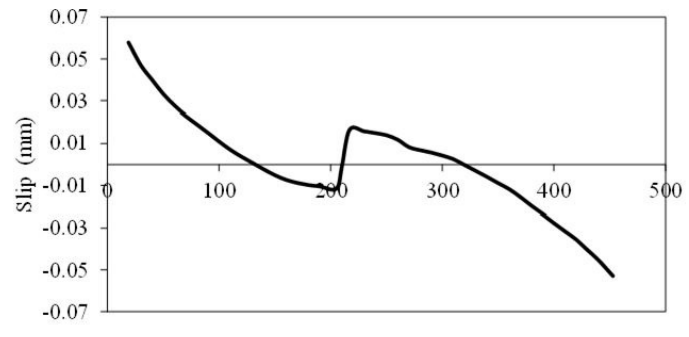

Distance to the left support $(\mathrm{cm})$

b) Slip due to prestressing

Figure 18 Slip over beam span at slab-beam interface.

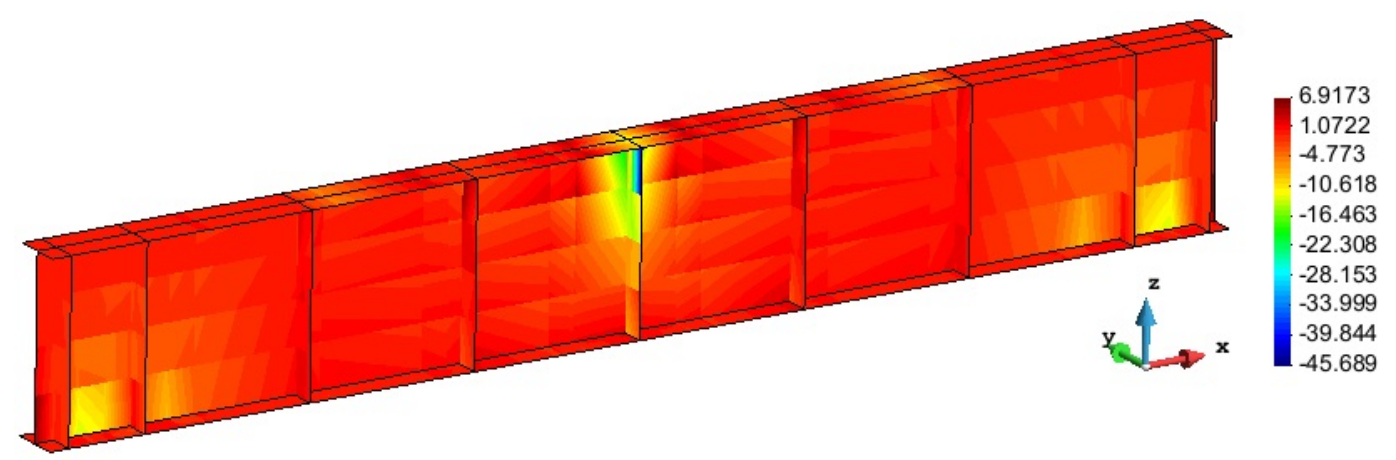

Figure 19 Von Mises stresses at ultimate load $\left(\mathrm{kN} / \mathrm{cm}^{2}\right)$.

\subsection{Short-term analysis of externally prestressed composite beams tested by Nie et al. (2009)}

The two-span PCCB4 (fold-line, two-tendon, internal prestressed beam) composite box beam tested in Nie et al. (2009) is selected in this section. Due to symmetry considerations only one half the beam is depicted in Figure 20(a). The cross section is made of a steel box supporting the RC slab as shown in Figure 20(b). The two tendons are anchored at the beam ends and at deviators zones, in which a change of tendons direction occurs. Two point loads are applied symmetrically to each span. Firstly, a prestressed force of $123.22 \mathrm{kN}$ is applied at each tendon, then the two point loads are gradually exerted up to beam failure. The reinforcing bar ratios in the longitudinal and transversal directions are $1.62 \%$ and $0.67 \%$, respectively. Concrete compressive strength is $31.4 \mathrm{MPa}$, the average yield strengths of the steel beam and slab reinforcement are $270 \mathrm{MPa}$ and $300 \mathrm{MPa}$, respectively. The tendon ultimate strength is $1860 \mathrm{MPa}$. Shear connectors are $8 \mathrm{~mm}$ in diameter, $45 \mathrm{~mm}$ in height and spaced in pairs every $80 \mathrm{~mm}$. One tendon area is $139 \mathrm{~mm}^{2}$.

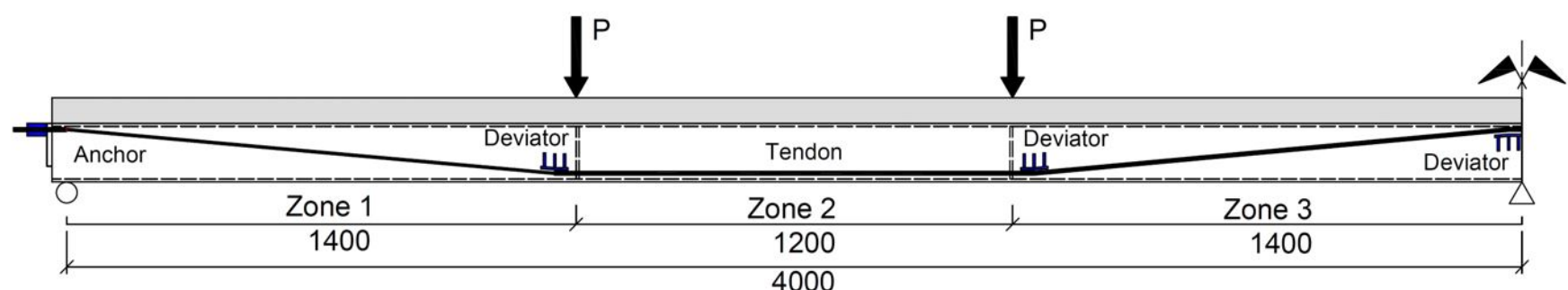

a) Half beam geometry and tendon profile

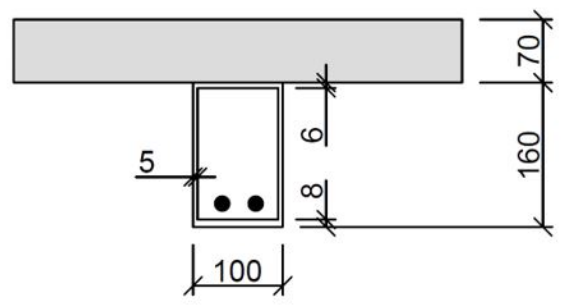

b) Cross-section

Figure 20 Geometry and loading of composite beam tested by Nie et al. (2009). [Units, mm]. 
Effect of tendon slipping at the deviators (unbonded case) is compared with its counterpart fully bonded, and load-deflection curves are plotted for this purpose (Figure 21(a)). As it may be observed, the fully bonded and unbonded cases provide nearly similar responses, which also compare well with the experimental data for various load levels, suggesting that slipping of the tendon is not important for the overall response of the composite beam. In Figure $21(b)$ is depicted the tendon force evolution as loading increases. Along with the experimental results, three curves labeled as Zone1, Zone2 and Zone3 are also plotted for comparison. These zones correspond to tendon segments among deviators and anchorage ends as already defined in Figure 20(a). Each curve defines a diferent stress fields according to its zone. Meanwhile, the unbonded situation predicts a nearly constant stress along its entire length as shown in Figure 22. Then, good matching is found for the tendon force evolution.

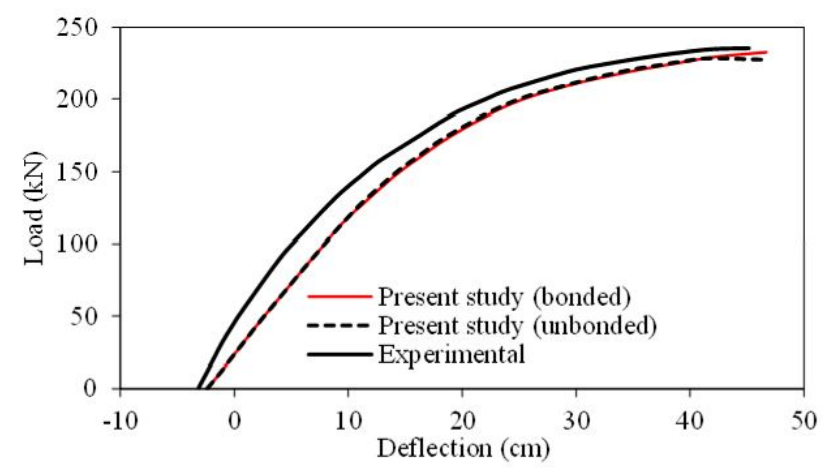

a) Load-deflection curve at midspan

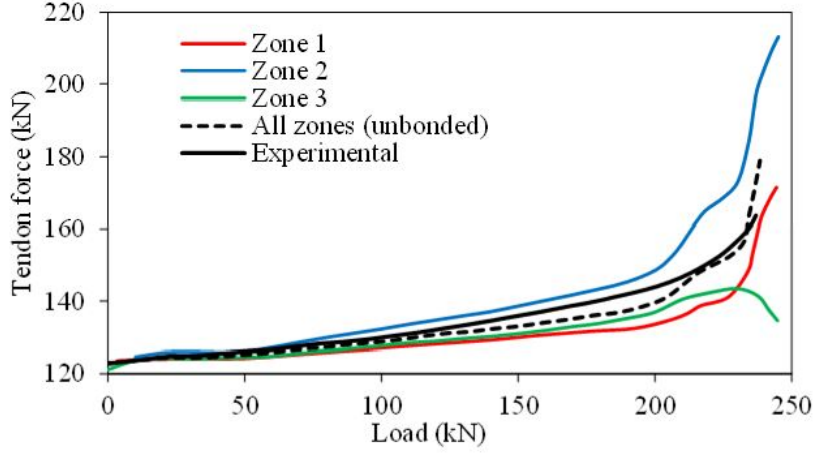

b) Tendon force evolution

Figure 21 Composite beam PCCB4 tested by Nie et al. (2009).

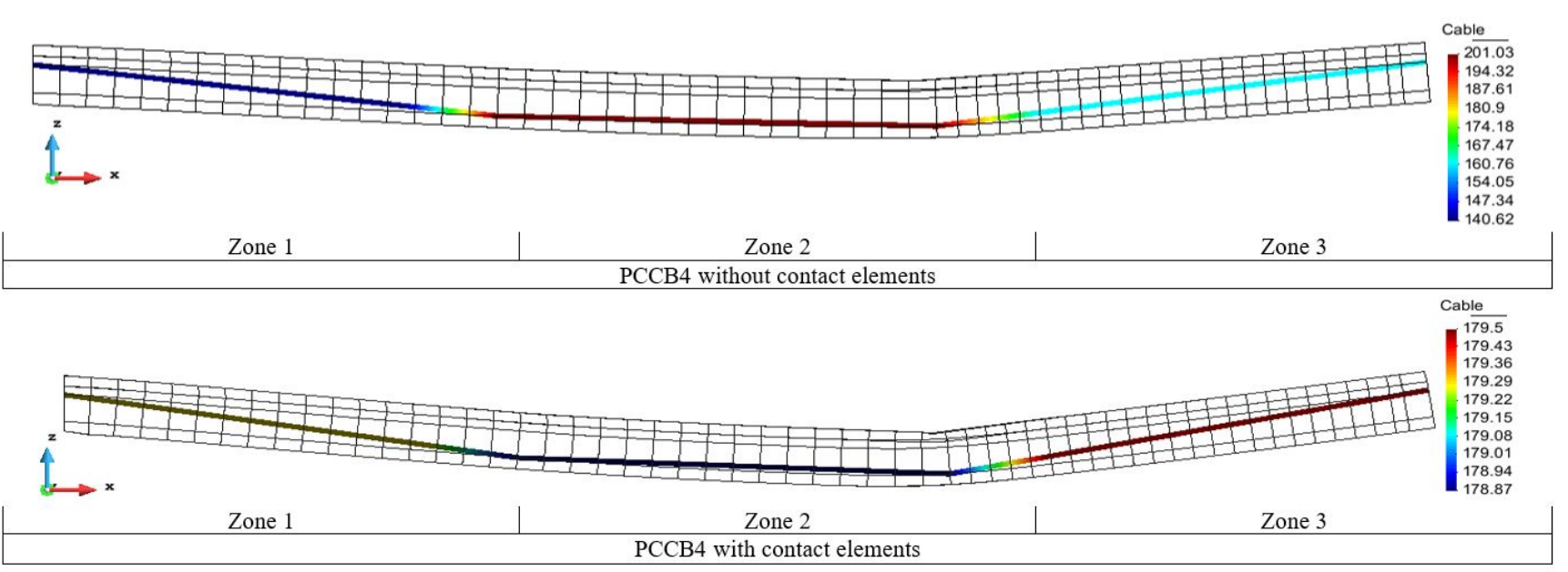

Figure 22 Tendon force $(\mathrm{kN})$ along beam span at ultimate load.

Otherwise, in Figure 23(a) is depicted the predicted cracking pattern at the top concrete layer of the RC slab at service load $P_{k}=146.76 \mathrm{kN}$ according to the FE model. Due to symmetry considerations only one span is displayed. As it can be seen, flexural cracks represented by blue lines are developed from the interior support up to a distance of $633 \mathrm{~mm}$, i.e., $15.8 \%$ of the span length. Meanwhile, compressive stresses represented by red circles are formed between point loads at the positive flexure region. This behavior is similar to that reported in the experimental test at this serviceability stage (Nie et al. 2009). Precisely, in Nie et al.'s work is proposed an equation to predict cracked zone lengths according to the applied degree of prestressing $\lambda=M_{0} / M_{k}$ in continuous beams, here $M_{0}$ is the moment needed to eliminate the compressive stress at the interior support and $M_{k}$ is the moment at the interior support due to service load $P_{k}$, excluding the prestressing effect. The performance of Nie et al.'s formula for various degrees of prestressing is depicted in Figure 23(b). According to this formula, the dimensionless crack length is $13.8 \%$ for the current example $(\lambda=0.255)$. This value is very close to $15.8 \%$ obtained by the FE analysis. Then, the obtained results support the statements established in some design guidelines, in which a cracked region of $15 \%$ at interior supports should be considered for service analyses. 

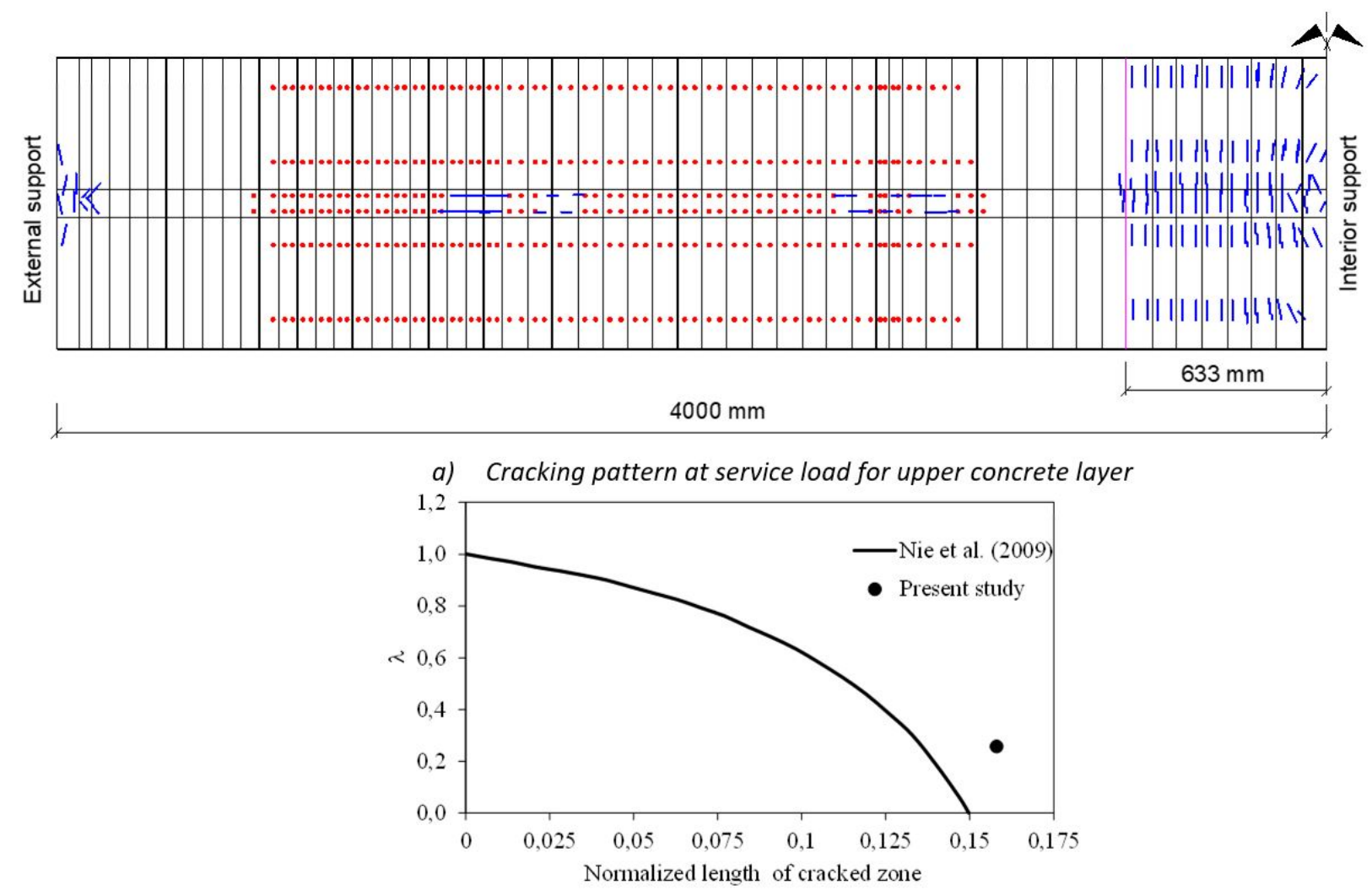

b) Dimensionless crack length versus degree of prestressing

Figure 23 Evaluation of crack length.

\section{CONCLUSIONS}

In this work, some aspects of the three-dimensional numerical modeling of steel-concrete composite beams with internal and external tendons are presented. For this purpose, a FE model resulting from the assemblage of other model techniques, which were initially intended for single RC elements is proposed. The model is able to deal with all types of nonlinearities of the involved materials as a consequence of the applied short- and long-term loads. Comments and suggestions are then given about the numerical modeling of these structures, in which emphasis is given to the theorical and numerical treatment of strains in unbonded internal tendons. Several examples of single RC specimens and steel-concrete composite beams with experimental dataset and other numerical results, subjected to both service and ultimate loads are reported herein to show model accuracy. Favourable agreement is found in all cases at the global and local level, in which tendon force evolutions are adequately predicted. Thus, the following conclusions can be draw from this study.

In the case of unbonded internal tendons, considering the stiffness of the tendon aims to speed the convergence ratio of the non-linear process and also assures it.

Ommiting slipping at the deviator-tendon interface can lead to innacurate results in the tendon force computation by predicting different stress values among deviator devices. When contact elements are introduced, a uniform tendon force is obtained, which is in accordance with the experimental evidence. However, it seems that the overall response of the structure expressed in terms of load-deflection curves remains unaffected by the inclusion of slipping at the tendon-deviator interface. Then, more examples are needed to generalize this point.

The prediction of local buckling still constitutes a limitation of the current FE model, but work is in progress in order to include its effect by assuming an initially disturbed geometry of the beam. Also, geometric nonlinearility is ongoing.

Further studies should include long-term analyses with external prestressing. In this case, the prestress loss will be due to steel relaxation only. Two examples with long-term loads were considered in this paper, the prestress loss for Dezi et al.'s composite beam after 70 years is $2.5 \%$, while this is $6.5 \%$ for the RC beam of Tao and Du (1985). Values of prestress loss around $15 \%$ are normally used in practice. In all situations prestressing action generates a camber that 
juxtaposed with deflections from vertical loads, thus indicating a correct implementation of the prestressed tendon formulation in the existing code.

A carefully evaluation of the shear connector stiffness is needed because it has a great influence on the initial slope of the load-deflection curves.

Next steps will include the simulation of the construction process of cable-stayed bridges with steel-concrete composite beams by means of the cantilever method, including time effects. For this purpose, the same catenary element implemented in this work may be used for simulating the supporting cables. Furthermore, the effect of early shrinkage in the RC slab should be also assessed.

\section{Acknowledgment}

The financial support provided by CAPES and CNPq is gratefully acknowledged.

Author's Contributions: Conceptualization, JLP Tamayo and IB Morsch; Methodology, MI Franco and IB Morsch; Investigation, MI Franco; Software, JLP Tamayo, MI Franco and AMM Wayar; Validation, MI Franco, AMM Wayar and JLP Tamayo; Writing-original draft, JLP Tamayo; Writing - review \& editing, JM Désir and IB Morsch; Supervision, IB Morsch.

Editor: Pablo Andrés Muñoz Rojas

\section{References}

Ayyub, B., Sohn, Y., Saadatmanesh, H. (1992a). Prestressed composite girders. I: Experimental study for negative moment, Journal of Structural Engineering 118: 2743-2762.

Ayyub, B., Sohn, Y., Saadatmanesh, H. (1992b). Prestressed composite girders. II: Analytical study for negative moment, Journal of Structural Engineering 118: 2763-2783.

Abu-Sena, A., Shabaan, I., Soliman, M., Gharib, K. (2018). Effect of geometrical properties on strength of externally prestressed steel-concrete composite beams, Proceedings of the Institution of Civil Engineers - Structures and Buildings, https://doi.org/10.1680/jstbu.17.00172.

Baskar, K., Shanmugam, N., Thevendran, V. (2002). Finite-element analysis of steel-concrete composite plate girder, Journal of Structural Engineering 128: 1158-1168.

Bujnak, J., Bouchair, A. (2005). Numerical model for steel concrete composite beam with partial shear connection, Proceedings of the European Conference on Steel Structures 4.3: 17-24.

Cao, G., Han, C., Dai, Y., Zhang, W. (2018). Long-term experimental study on prestressed steel-concrete composite continuous box beams, Journal of Bridge Engineering 23: 04018067-1-11.

Coarita, E., Flores, L. (2015). Nonlinear analysis of structures cables-truss, International Journal of Engineering and Technology 7: 160-169.

Chen, Z., Zhang, S. (2018). EM-Based monitoring and probabilistic analysis of prestress loss of bonded tendons in PSC beams, Advances in Civil Engineering 2018: 1-9. https://doi.org/10.1155/2018/4064362.

Dias, M., Tamayo, J., Morsch, I. (2015). Time dependent finite element analysis of steel-concrete composite beams considering partial interaction, Computers and Concrete 15: 687-707.

Dezi, L., Leoni, G., Tarantino, A. (1995). Time dependent analysis of prestressed composite beams, Journal of Structural Engineering 121: 621-633.

Dezi, L., Leoni, G., Tarantino, A. (1996). Algebraic methods for creep analysis of continuous composite beams, Journal of Structural Engineering 122: 423-30.

El-Zohairy, A., Salim, H., Shaaban, H., Mustafa, S., El-Shihy, A. (2015). Finite-element modeling of externally posttensioned composite beams, Journal of Bridge Engineering 20:04015018-1-11. 
El-Zohairy, A., Salim, H., Shaaban, H. (2017). Finite element analysis and parametric study of continuos steel-concrete composite beams stiffined with post-tensioned tendons, Advances in Structural Engineering 21:933-945.

Fabregat, P. (1988). Nonlinear model for the analysis of PC plates and shells (in Spanish), Doctoral Thesis, Universidad Politecnica de Catalunya.

Figueiras, J., Póvoas, R. (1994). Modelling of prestress in non-linear analysis of concrete structures, Computers and Concrete 53: 173-187.

Guo, T., Chen, Z., Lu S., Yao R. (2018). Monitoring and analysis of long-term prestress losses in post-tensioned concrete beams, Measurement 122: 573-581.

Jiang, L., Huang, Z., Zhou, W., Xu, X. (2014). Mechanical behavior research of long span prestressed steel-concrete composite beam, Material Research Innovations 18: 28-32.

Liang, Q., Uy, B., Bradford, M., Ronagh, H. (2005). Strength analysis of steel-concrete composite beams in combined bending and shear, Journal of Structural Engineering 131: 1593-1600.

Lou, T., Lopes, S., Lopes, A. (2016). Numerical modeling of externally prestressed steel-concrete composite beams, Journal of Constructional Steel research 121: 229-236.

Lou, T., Lopes, S., Lopes, A. (2013). Nonlinear and time-dependent analysis of continuos unbonded prestressed concrete beams, Computers and Structures 119: 166-176.

Moreira, L., Sousa, J., Parente, E. (2018). Nonlinear finite element simulation of unbounded prestressed concrete beams, Engineering Structures 170: 167-177.

Moscoso, A., Tamayo, J., Morsch, I. (2017). Numerical simulation of external pre-stressed steel-concrete composite beams, Computers and Concrete 19: 191-201.

NBR 6118 (2014). Design of concrete structures-Procedures. Brazilian Association of Technical Regulations. Rio de Janeiro, RJ. Brazil.

Nie, J., Tao, M., Cai, C. S., Li, S. (2009). Deformation analysis of prestressed continuous steel-concrete composite beams, Journal of Structural Engineering 135: 1377-1389.

Razaqpur, G., Nofal, M., Shedid, M., Esfandiari, A. (2012). Nonlinear behavior of steel-concrete composite bridges: finite element modeling and experimental verification, Canadian Journal of Civil Engineering 39: 191-202.

Reginato, L., Tamayo, J., Morsch, I. (2018). Finite element study of effective width in steel-concrete composite beams under long-term service loads, Latin American Journal of Solids and Structures 15: 1-25.

Sebastian, W., McConnel, R. (2000). Nonlinear FE analysis of steel-concrete composite structures, Journal of Structural Engineering 126: 662-674.

Stojanovic, B., Kostic, S. (2015). Time-dependent analysisof composite and prestressed beams using the slope deflection method, Archived of Applied Mechanics 85: 257-272.

Tao, X., Du, G. (1985). Ultimate stress of unbounded tendons in partially prestressed concrete beams, PCI Journal 30: 72-91.

Tamayo, J., Awruch, A. (2015). Numerical simulation of reinforced concrete nuclear containment under extreme loads, Structural Engineering and Mechanics 58: 799-823.

Tamayo, J., Morsch, I., Awruch, A. (2015). Short-time numerical analysis of steel-concrete composite beams, Journal of the Brazilian Society of Mechanical Science and Engineering 37: 1097-1109.

Tamayo, J., Morsch, I., Awruch, A. (2013a). Static and dynamic analysis of reinforced concrete shells, Latin American Journal of Solids and Structures 10: 1109-1134.

Tamayo, J., Awruch, A., Morsch, I. (2013b). Numercal modeling of reinforced concrete structures: static and dynamic analysis, REM-Revista Escola de Minas 66: 425-430.

Xue, W., Ding, M., He, C., Li, J. (2008). Long-term behavior of prestressed composite beams at service loads for one year, Journal of Structural Engineering 134: 930-937. 